\title{
Correlation Between Shear Wave Velocity (Vs) and SPT Resistance $(N)$ for Roorkee Region
}

\author{
Bablu Kirar $^{1}$ - B. K. Maheshwari ${ }^{1} \cdot$ Pradeep Muley $^{1}$
}

Received: 23 December 2015/Accepted: 12 February 2016/Published online: 11 March 2016

(C) Springer International Publishing Switzerland 2016

\begin{abstract}
For ground improvement, assessment of damage during an earthquake is very important issue which in turn depends on the ground motion. The characteristics of an earthquake motion at a site depend on the shear wave velocity $\left(V_{s}\right)$. The shear wave velocity profile at a site may not be readily available however, the numbers of blows $(N)$ from standard penetration test (SPT) are readily available. This paper presents a development of reliable correlation between $V_{s}$ measured by multi channel analysis of surface wave tests and $N$ measured using SPT at various sites in Roorkee region. These tests have been carried out at ten different sites in Roorkee region (within a radius of $30 \mathrm{~km}$ ). The SPT samples are tested in the laboratory for index properties. Roorkee is situated in high seismic zone, therefore the study is important for this region. Based on the statistical assessments, an empirical correlation between $V_{s}$ and $N$ was developed. This is done separately for all types of soils, sands only and clays only. The developed relations fall within the range of other relations developed worldwide for other sites. A comparison with available relations is also presented. The proposed relations will be helpful in seismic microzonation of the region as ground motion is one of the important parameters.
\end{abstract}

Keywords Shear wave velocity $\cdot$ Number of blows . MASW · Standard penetration test · Correlations

B. K. Maheshwari

bkmaheshwari.iitr@gmail.com; bkmahfeq@iitr.ac.in

Bablu Kirar

bablu_iitg@yahoo.in

Pradeep Muley

mulepdeq@iitr.ac.in

1 Department of Earthquake Engineering, IIT, Roorkee, India

\section{Introduction}

The characteristics of an earthquake motion at a site are significantly affected by the presence of soil deposits. The ground motion characteristics are evaluated either by simplified site classification method or by carrying out rigorous site specific ground response analysis. For all these methods, shear wave velocity $\left(V_{s}\right)$ is the most important parameter, which represents the stiffness of the soil layers. The shear wave velocity profile at a site is usually obtained by carrying out wave propagation tests. But it is often not economically feasible to conduct these tests at all the sites. However, the numbers of blows $(N)$ from standard penetration test (SPT) are readily available for many sites where geotechnical investigations are carried out. In this view, a reliable empirical correlation between $V_{s}$ and $N$ would be of a considerable advantage. Roorkee is a small city in northern India about $200 \mathrm{~km}$ from New Delhi and lies in high seismic zone IV [1].

In this study, an attempt has been made to develop a reliable correlation between $V_{s}$ and $N$ for soils of Roorkee region. The shear wave velocity has been measured by multichannel analysis of surface wave (MASW) tests and SPTs are carried out at ten sites within a radius of $30 \mathrm{~km}$ from Roorkee city. The correlation between $V_{s}$ and $N$ developed for the study area is compared with the existing correlation in the literature.

Worldwide and within India, many attempts have been made to correlate values of $V_{s}$ with available soil parameters such as $N$ value. For Chennai city, Boominathan et al. [2] had determined the $V_{s}$ using available data of $N$ value of soil and correlations given by JRA [3]. For Bangalore city, Sitharam and Anbazhagan [4] had carried out MASW survey for about 38 locations very close to the available SPT borehole locations, and these were used to generate 
correlation between shear wave velocity and corrected $N$ values. For Delhi city, Hanumantharao and Ramana [5] had measured shear wave velocity using SASW for 80 locations to a depth of 20-32 m and developed correlations between $V_{s}$ and $N$ value. For Ganga Basin, Maheshwari et al. [6] have carried out MASW and SPT for two locations namely Dhanauri and Roshnabad and developed correlations between $V_{s}$ and $N$ value.

In Japan, several researchers developed correlations between $V_{s}$ and $N$, considering the geological age and soil type [7-9]. Jafari et al. [10] shown correlations for Tehran. In USA and Taiwan, similar studies were carried out and correlations had been developed between $V_{s}$ and $N$ using uncorrected $N$ value $[11,12]$. However, the correlation of $V s-N$ for the Roorkee region (which is of local interest) has not been reported in the literature. In the present work, $V_{s}-$ $N$ relationship for ten sites in Roorkee region has been investigated. For this, the shear wave velocity investigation was performed using MASW tests and $N$ values were determined using SPTs. An empirical relation $\left(V_{s}-N\right)$ applicable to all the ten sites was evaluated based on these tests. This is carried out separately for three types of soil deposits i.e. all types of soils, sandy soils and clayey soils.

\section{Geotechnical Investigation}

The geotechnical investigations were carried out using standard penetration tests (SPT) according to IS 2131 [13] and laboratory tests of the samples collected from all the ten sites. The locations of all ten sites are shown in Fig. 1 and Table 1 gives details of all ten sites i.e. location, depth of water table (WT), depth of borehole and number of samples collected using SPT and tested in the laboratory. Here five sites [1, 7-10] are within the IIT Roorkee campus, while site 2 is very near to Roorkee city and others are outside Roorkee but within $30 \mathrm{~km}$ radius. It can be observed that the range of depth of borehole is in between 6 and $12.5 \mathrm{~m}$, except for one site. Drilling could not be done beyond $12.5 \mathrm{~m}$. The water table is at shallow depth i.e. $\leq 6 \mathrm{~m}$, Kirar and Maheshwari [14] examined the dynamic soil properties at high strain using cyclic triaxial tests for four sites [2-5] listed in Table 1, Muley et al. [15] evaluated liquefaction potential of first five sites listed in Table 1. Index properties and SPT resistance of all the ten sites has been evaluated and discussed below.

The soil samples were collected from different depths at the ten sites using the SPTs. The laboratory test were carried out on all the samples collected to evaluate their index properties i.e. grain size distribution [16] specific gravity [17] maximum and minimum void ratio, coefficient of uniformity, coefficient of curvature, dry unit weight and relative density [18]. For example, for DEQ Campus site, total 7 samples were collected from different depths using SPT. Depths from which samples were collected are 0.75 , $1.5,3,4.5,6,7.5$ and $9 \mathrm{~m}$. All these samples were examined to know their index properties. Grain size distribution (GSD) curves for sand samples collected from depths 0.75 , 1.5, 7.5 and $9 \mathrm{~m}$ are given in Fig. 2. It can be observed that all the particles are less than $0.6 \mathrm{~mm}$ size and no particles are less than $0.075 \mathrm{~mm}$, therefore for all these four depths, soils falls in the range of fine to medium sand and classified as SP. The samples collected from depths 3, 4.5 and $6 \mathrm{~m}$, are of clays therefore, the soil classification is evaluated based on their plasticity index values. The above exercise is repeated for all other sites too and it was observed that there are differences in percentage of fines. Effect of depth on GSD is difficult to generalize.

Table 2 shows the type of soil, range of fine contents, range of $N$ and range of $V_{s}$ for all the ten sites. It can be observed from Table 2 that the maximum depth of borehole is $12.5 \mathrm{~m}$. Range of $N$ is (2-18) and range of $V_{s}$ is $(125-350 \mathrm{~m} / \mathrm{s})$. It can be observed that the fine content varies from 2 to $33 \%$ for all the sites except Khempur, where fine contents are quite high due to clay samples. Also it can be observed that for the sites where the fine contents are high (Bahadrabad, Haridwar, Solani Kunj and Convocation Hall Ground) the $N$ values are relatively higher.

Figure 3 presents variation of $N$ values with depth for all the ten sites. It can be observed from these soil profiles that the Solani Riverbed and Bhagwanpur sites are weakest ( $N$ : 2-12) and Bahadrabad and Haridwar sites are strongest ( $N$ : 7-13). Within the IIT Roorkee campus, DEQ campus site is weaker and other four sites are relatively stronger.

\section{Geophysical Investigation}

Traditionally, SPT was found to be popular among geotechnical engineers in order to estimate the strength of the soil. The down hole or cross hole profiling methods allow in situ measurements of the shear-wave velocity with depth. However, the performance of these methods for site characterization can be rather difficult and expensive in urban areas because these methods require boreholes [19, 20]. To overcome these problems, non-invasive seismic exploration has emerged as a promising alternative to estimate the shear wave profiles and the resonance frequencies. In these seismic explorations, the data acquisition process is relatively economical and fast, and can be implemented in urban areas without much difficulty. In the present study, MASW tests have been used to derive the 1-D velocity model of each site.

The MASW measurements were made at all ten sites in Roorkee region. The survey was conducted by deploying 


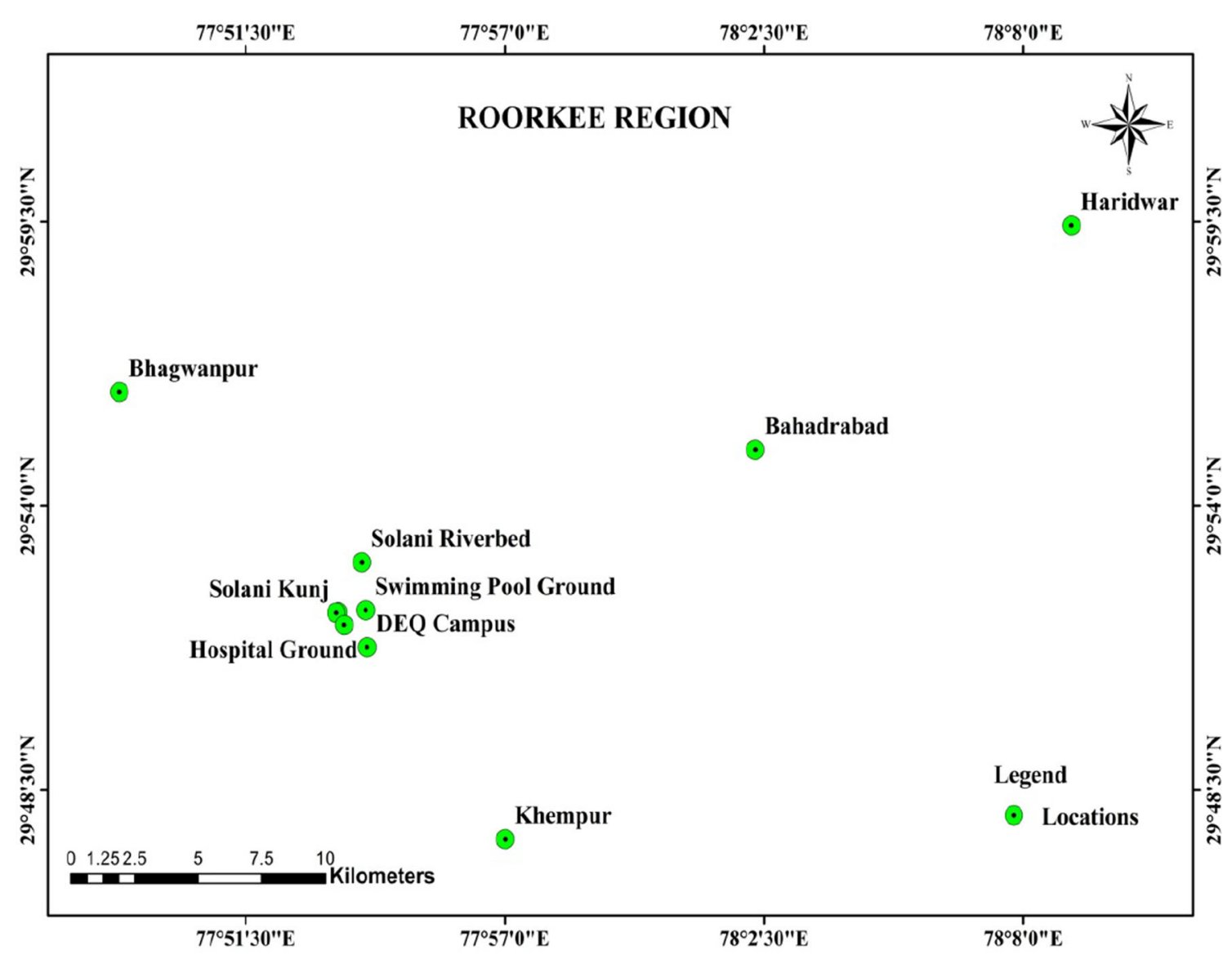

Fig. 1 Location of sites

Table 1 Details of sites

\begin{tabular}{|c|c|c|c|c|c|c|}
\hline S. no. & Sites & Longitude & Latitude & WT (m) & $\begin{array}{l}\text { Bore hole } \\
\text { depth (m) }\end{array}$ & $\begin{array}{l}\text { Number of } \\
\text { samples }\end{array}$ \\
\hline 1 & DEQ campus (IIT Roorkee) & $\mathrm{E} 077^{\circ} 54.075^{\prime}$ & $\mathrm{N} 29^{\circ} 51.262^{\prime}$ & 4.5 & 9.0 & 7 \\
\hline 2 & Solani Riverbed (Roorkee) & $\mathrm{E} 077^{\circ} 53.965^{\prime}$ & $\mathrm{N} 29^{\circ} 52.907^{\prime}$ & 2.0 & 3.5 & 4 \\
\hline 3 & Bhagwanpur & $\mathrm{E} 077^{\circ} 48.820^{\prime}$ & $\mathrm{N} 29^{\circ} 56.203^{\prime}$ & 2.5 & 8.0 & 7 \\
\hline 4 & Bahadrabad & $\mathrm{E} 078^{\circ} 02.307^{\prime}$ & $\mathrm{N} 29^{\circ} 55.087^{\prime}$ & 6.0 & 9.0 & 8 \\
\hline 5 & Haridwar & $\mathrm{E} 078^{\circ} 09.019^{\prime}$ & $\mathrm{N} 29^{\circ} 59.420^{\prime}$ & NA & 6.0 & 5 \\
\hline 6 & Khempur & $\mathrm{E} 077^{\circ} 57.006^{\prime}$ & $\mathrm{N} 29^{\circ} 47.545^{\prime}$ & 2.0 & 9.0 & 7 \\
\hline 7 & Solani Kunj (IIT Roorkee) & $\mathrm{E} 077^{\circ} 53.420^{\prime}$ & $\mathrm{N} 29^{\circ} 51.930^{\prime}$ & 5.0 & 8.0 & 7 \\
\hline 8 & Convocation Hall Ground (IIT Roorkee) & $\mathrm{E} 077^{\circ} 53.465^{\prime}$ & $\mathrm{N} 29^{\circ} 51.940^{\prime}$ & 6.0 & 12.5 & 10 \\
\hline 9 & Swimming Pool Ground (IIT Roorkee) & $\mathrm{E} 077^{\circ} 54.047^{\prime}$ & $\mathrm{N} 29^{\circ} 51.979^{\prime}$ & 6.0 & 12.0 & 9 \\
\hline 10 & Hospital Ground (IIT Roorkee) & $\mathrm{E} 077^{\circ} 53.591^{\prime}$ & $\mathrm{N} 29^{\circ} 51.693^{\prime}$ & 6.0 & 12.0 & 10 \\
\hline
\end{tabular}

24 vertical spike based geophones, with a maximum frequency of $2 \mathrm{~Hz}$ in a linear array with $4 \mathrm{~m}$ spacing and connected to a multichannel recorder. A sledge hammer $(10 \mathrm{~kg})$ and an elastometer aided weight drop hammer (EAWDH) of $60 \mathrm{~kg}$ was used as the active source, for hitting a $300 \mathrm{~mm} \times 300 \mathrm{~mm}$ and $25 \mathrm{~mm}$ thick metal plate placed at one end of geophone line. Data processing was carried out using SurfSeis 2.0 software [21].

Variations of shear wave velocity $\left(V_{s}\right)$ with depth for all ten sites are shown in Fig. 4. Though for all these sites, results of $V_{s}$ from MASW tests were available for higher depths. However in Fig. 4, results are shown only up to the 
depth for which $N$ values are available (Fig. 3). It can be observed from Fig. 4 that there is not large variation in $V_{s}$ with depth. For example, shear wave velocity is quite small

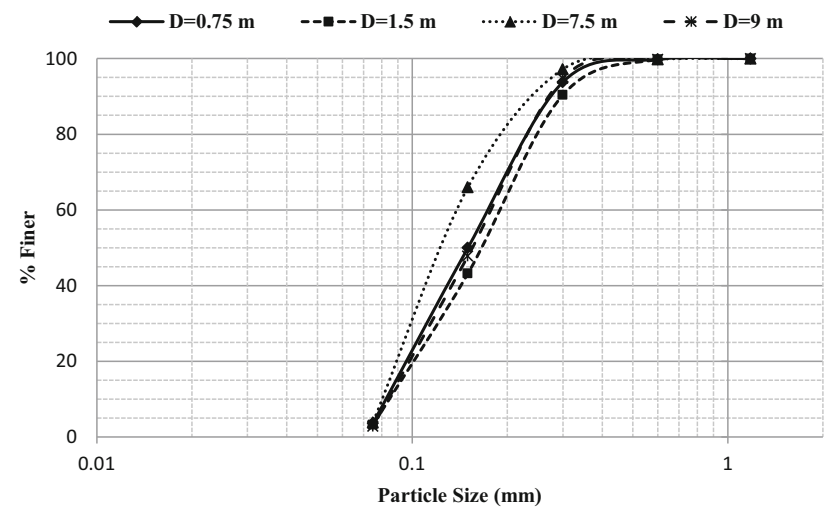

Fig. 2 Grain size distribution for DEQ campus site
$\left(V_{s}<170 \mathrm{~m} / \mathrm{s}\right.$ ) for Solani Riverbed and Bhagwanpur while relatively greater $\left(V_{s}>270 \mathrm{~m} / \mathrm{s}\right)$ for Bahdrabad, Haridwar and Convocation Hall Ground (at depth $>4.5 \mathrm{~m}$ ). For other five remaining sites, the shear wave velocity is in the medium range $(170-270 \mathrm{~m} / \mathrm{s})$. Thus observations of MASW tests are correlating well with those using SPTs.

\section{Proposed Empirical Relation for $V_{s}-N$}

A number of empirical relations are available for shear wave velocity $\left(V_{s}\right)$ and penetration resistance $(N)$ in the literature for different soils as listed in Table 3. All of these correlations are based on uncorrected $\mathrm{V}_{\mathrm{S}}$ and uncorrected $\mathrm{N}$ value. It can be observed that all the relations given in Table 3 are in the following format.

$V_{s}=a \times N^{b}$
Table 2 Type of soil, range of fine contents, range of $N$ and range of $V_{s}$ for all the ten sites

\begin{tabular}{|c|c|c|c|c|}
\hline S. no. & Site name & Depth (m) & Soil type & Remark \\
\hline \multirow[t]{3}{*}{1} & \multirow[t]{3}{*}{ DEQ Campus } & $0-3$ & SP & $N(5-11)$ \\
\hline & & $3-6$ & $\mathrm{CL}$ & $V_{s}(200-230 \mathrm{~m} / \mathrm{s})$ \\
\hline & & $6-9$ & SP & Fines $(2.4-4 \%)$ \\
\hline \multirow[t]{3}{*}{2} & \multirow[t]{3}{*}{ Solani Riverbed } & \multirow[t]{3}{*}{$0-3.5$} & \multirow[t]{3}{*}{ SP } & $N(4-12)$ \\
\hline & & & & $V_{s}(140 \mathrm{~m} / \mathrm{s})$ \\
\hline & & & & Fines $(2.6-3 \%)$ \\
\hline \multirow[t]{3}{*}{3} & \multirow[t]{3}{*}{ Bhagwanpur } & $0-4.5$ & SP & $N(2-12)$ \\
\hline & & $4.5-6$ & $\mathrm{CL}$ & $V_{\mathrm{s}}(160-170 \mathrm{~m} / \mathrm{s})$ \\
\hline & & $6-8$ & SP & Fines $(2.2-15 \%)$ \\
\hline \multirow[t]{3}{*}{4} & \multirow[t]{3}{*}{ Bahadrabad } & $0-4.5$ & SP & $N(8-13)$ \\
\hline & & $4.5-6.5$ & $\mathrm{CL}$ & $V_{\mathrm{s}}(320-350 \mathrm{~m} / \mathrm{s})$ \\
\hline & & $6.5-9$ & SP & Fines $(18.8-32.6 \%)$ \\
\hline \multirow[t]{3}{*}{5} & \multirow[t]{3}{*}{ Haridwar } & \multirow[t]{3}{*}{$0-6$} & \multirow[t]{3}{*}{ SP } & $N(7-13)$ \\
\hline & & & & $V_{\mathrm{s}}(270-280 \mathrm{~m} / \mathrm{s})$ \\
\hline & & & & Fines $(20.8-32.6 \%)$ \\
\hline \multirow[t]{3}{*}{6} & \multirow[t]{3}{*}{ Khempur } & \multirow[t]{3}{*}{$0-9$} & \multirow[t]{3}{*}{$\mathrm{CL}$} & $N(4-10)$ \\
\hline & & & & $V_{\mathrm{s}}(170-180 \mathrm{~m} / \mathrm{s})$ \\
\hline & & & & Fines (all clays) \\
\hline \multirow[t]{3}{*}{7} & \multirow[t]{3}{*}{ Solani Kunj } & $0-45$ & SP & $N(6-17)$ \\
\hline & & $4.5-6$ & $\mathrm{CL}$ & $V_{\mathrm{s}}(180-310 \mathrm{~m} / \mathrm{s})$ \\
\hline & & $6-9.5$ & SP & Fines $(9.8-26.8 \%)$ \\
\hline \multirow[t]{3}{*}{8} & \multirow[t]{3}{*}{ Convocation Hall Ground } & $0-7.5$ & SP & $N(6-16)$ \\
\hline & & $7.5-9$ & $\mathrm{CL}$ & $V_{\mathrm{s}}(180-280 \mathrm{~m} / \mathrm{s})$ \\
\hline & & $9-15$ & SP & Fines $(2.4-32.9 \%)$ \\
\hline \multirow[t]{3}{*}{9} & \multirow[t]{3}{*}{ Swimming Pool Ground } & $0-7.5$ & SP & $N(2-17)$ \\
\hline & & $7.5-9$ & $\mathrm{CL}$ & $V_{\mathrm{s}}(125-280 \mathrm{~m} / \mathrm{s})$ \\
\hline & & $9-12$ & SP & Fines $(6.7-13.1 \%)$ \\
\hline \multirow[t]{3}{*}{10} & \multirow[t]{3}{*}{ Hospital Ground } & $0-10.5$ & SP & $N(2-18)$ \\
\hline & & $10.5-12$ & $\mathrm{CL}$ & $V_{\mathrm{s}}(150-270 \mathrm{~m} / \mathrm{s})$ \\
\hline & & & & Fines $(4.2-13.5 \%)$ \\
\hline
\end{tabular}


Fig. 3 Variation of penetration resistance $(N)$ with depth for all sites

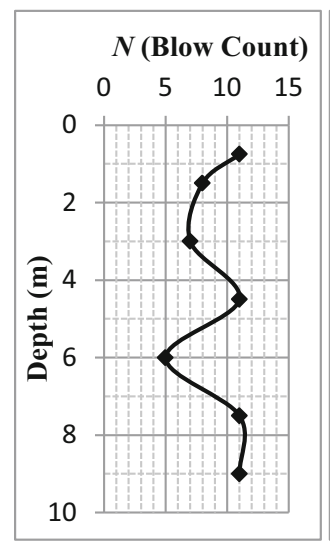

(a) DEQ Campus

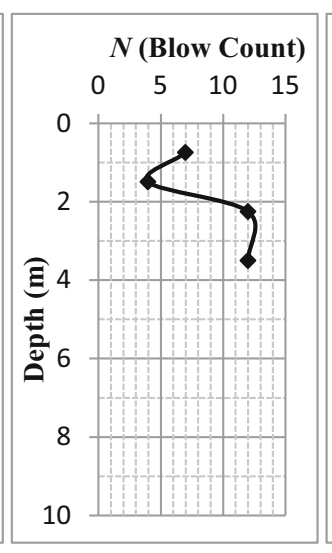

(b) Solani Riverbed

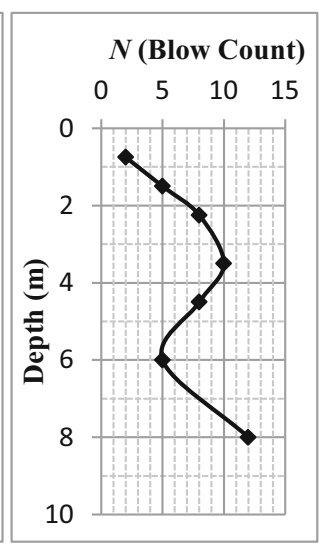

(c) Bhagwanpur

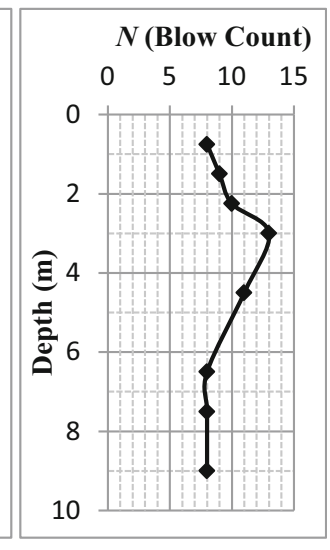

(d) Bahadrabad

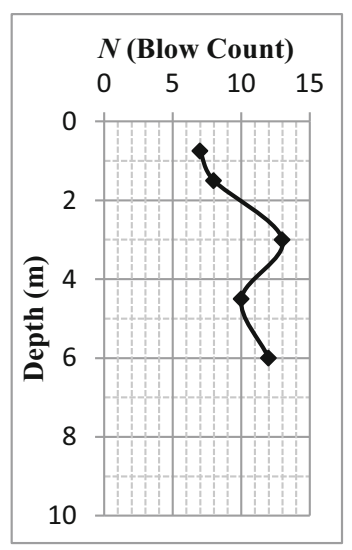

(e) Haridwar

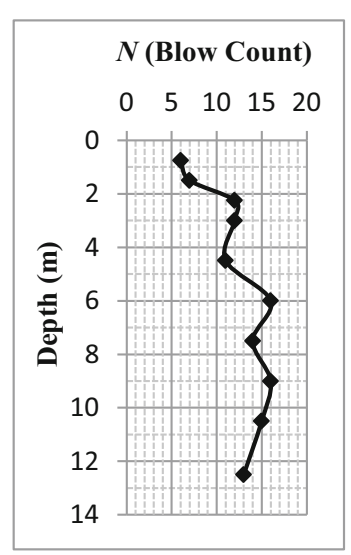

(h) Convocation Hall Ground

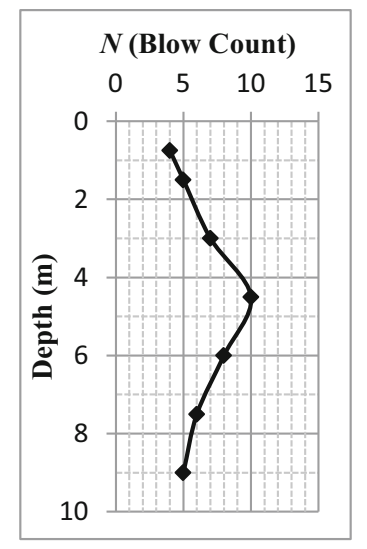

(f) Khempur

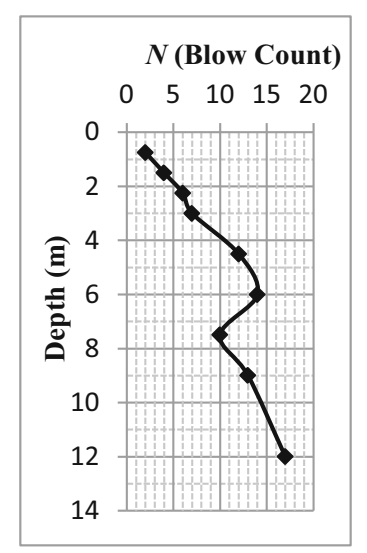

(i) Swimming Pool Ground

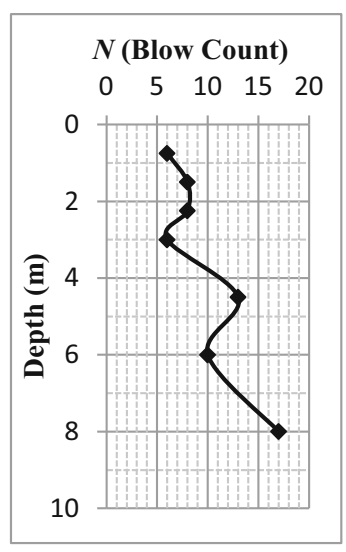

(g) Solani Kunj

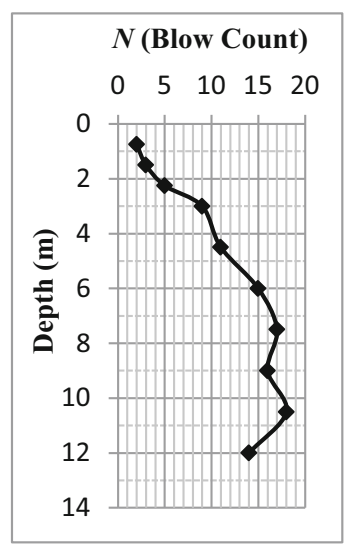

(j) Hospital Ground where $a$ and $b$ are coefficients varying for different locations and types of soil, Further it can be observed that for all soils, most of the researchers proposed the value of $a$ in the range of (82-95) and $b$ in the range of (0.3-0.45).

In the present study also uncorrected values have been used for both $V_{s}$ and $N$ because results using this are in good agreement with existing literature as verified in next section. Further the proposed relationships from the present study are also kept in the same format as of Eq. 1.

\section{All Soils}

In this study, 74 data pairs $\left(V_{s}\right.$ and $\left.N\right)$ were employed in the assessments. The correlations were developed using a 
Fig. 4 Variations of shear wave velocity $\left(V_{s}\right)$ with depth for all sites

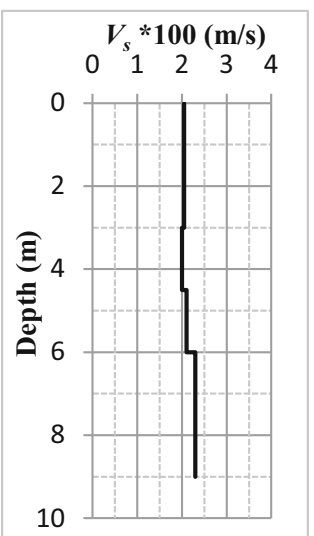

(a) DEQ campus

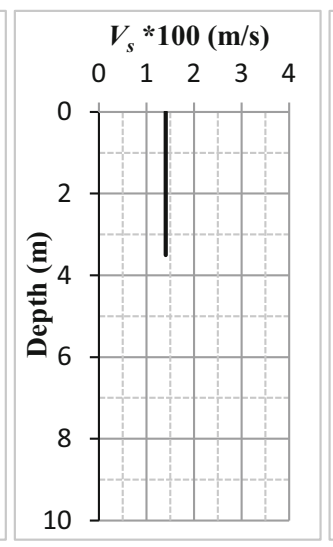

(b) Solani riverbed

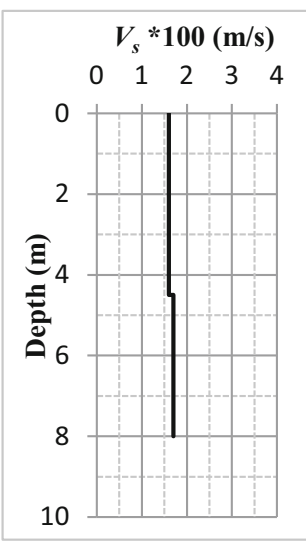

(c) Bhagwanpur

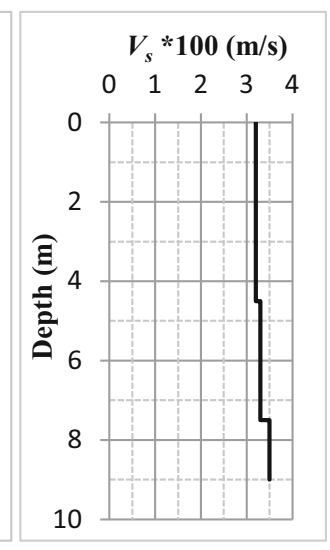

(d) Bahadrabad

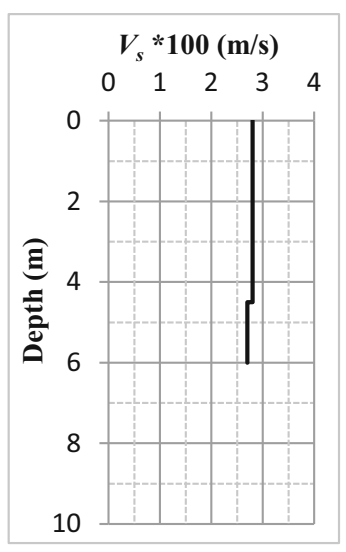

(e) Haridwar

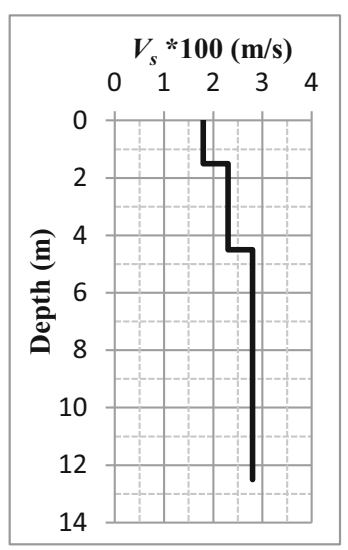

(h) Convocation Hall Ground

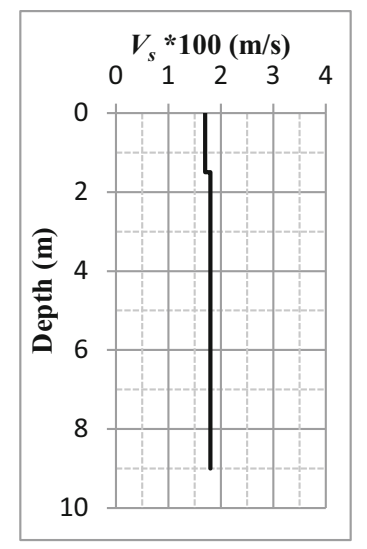

(f) Khempur

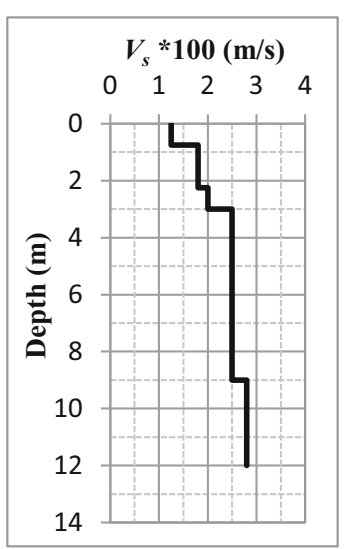

(i) Swimming Pool Ground

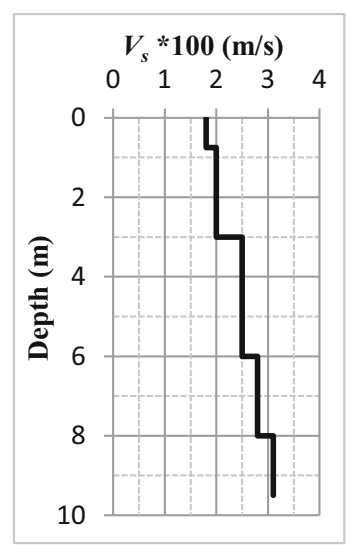

(g) Solani Kunj

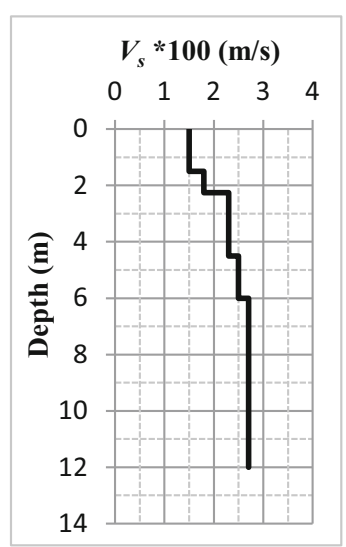

(j) Hospital Ground simple regression analysis. In the analyses, new relationships were proposed between $V_{s}(\mathrm{~m} / \mathrm{s})$ and $N$ values. However, before this, effect of correction on $N$ values has been examined.

The comparisons of the results of the present study are made with the equations recommended by five other researchers i.e. Hanumantharao and Ramana [5], Ohba and
Toriumi [7], Imai [8], Jafari et al. [10] and Athanasopoulos [25]. Figure 5a shows this comparison, when in the present study uncorrected $V_{s}$ and uncorrected $N$ for all soils is used. Figure $5 \mathrm{~b}$ shows this comparison when in present study uncorrected $V_{s}$ and corrected $N$ for all soils is used. For this, the measured $\mathrm{N}$ value was corrected for overburden pressure by using the following relation 
Table 3 Some existing correlations between $V_{\mathrm{s}}$ and $N$

\begin{tabular}{llll}
\hline Author(s) & $V_{\mathrm{s}}(\mathrm{m} / \mathrm{s})$ & & Clays \\
\cline { 2 - 4 } & All soils & Sands & - \\
\hline Hanumantharao and Ramana [5] & $V_{\mathrm{s}}=82.6 N^{0.430}$ & $V_{\mathrm{s}}=79.0 N^{0.434}$ & - \\
Maheshwari et al. [6] & - & $V_{\mathrm{s}}=95 N^{0.300}$ & - \\
Ohba and Toriumi [7] & $V_{\mathrm{s}}=84 N^{0.310}$ & - & $V_{\mathrm{s}}=80.2 N^{0.292}$ \\
Imai [8] & $V_{\mathrm{s}}=91 N^{0.340}$ & $V_{\mathrm{s}}=80.6 N^{0.331}$ & - \\
Ohta and Goto [9] & $V_{\mathrm{s}}=85.35 N^{0.348}$ & $V_{\mathrm{s}}=88.0 N^{0.340}$ & $V_{\mathrm{s}}=100.0 N^{0.330}$ \\
Jafari et al. [10] & $V_{\mathrm{s}}=121.0 N^{0.270}$ & $V_{\mathrm{s}}=80.0 N^{0.330}$ & - \\
Seed and Idriss [11] & $V_{\mathrm{s}}=61 N^{0.500}$ & - & $V_{\mathrm{s}}=114.4 N^{0.310}$ \\
Lee [12] & - & $V_{\mathrm{s}}=57.4 N^{0.490}$ & - \\
Sykora and Stokoe [22] & - & $V_{\mathrm{s}}=100.5 N^{0.290}$ & - \\
Okamoto et al. [23] & - & $V_{\mathrm{s}}=125.0 N^{0.300}$ & $V_{\mathrm{s}}=165.7 N^{0.190}$ \\
Pitilakis et al. [24] & - & $V_{\mathrm{s}}=162.0 N^{0.170}$ & - \\
Athanasopoulos [25] & $V_{\mathrm{s}}=107.6 N^{0.360}$ & - & $V_{\mathrm{s}}=184.2 N^{0.170}$ \\
Raptakis et al. [26] & - & $V_{\mathrm{s}}=123.4 N^{0.290}$ & $V_{\mathrm{s}}=\mathrm{z} 97.9 N^{0.269}$ \\
Hasancebi and Ulusay [27] & $V_{\mathrm{s}}=90 N^{0.309}$ & $V_{\mathrm{s}}=90.8 N^{0.319}$ & $V_{\mathrm{s}}=89.31 N^{0.358}$ \\
Uma Maheswari et al. [28] & $V_{\mathrm{s}}=95.64 N^{0.301}$ & $V_{\mathrm{s}}=100.53 N^{0.265}$ & - \\
Esfehanizadeh et al. [29] & - & $V_{\mathrm{s}}=107.2 N^{0.34}$ & - \\
Fatehnia et al. [30] & - & $V_{\mathrm{s}}=77.1 N^{0.355}$ & $V_{\mathrm{s}}=77.1 N^{0.355}$ \\
\hline
\end{tabular}
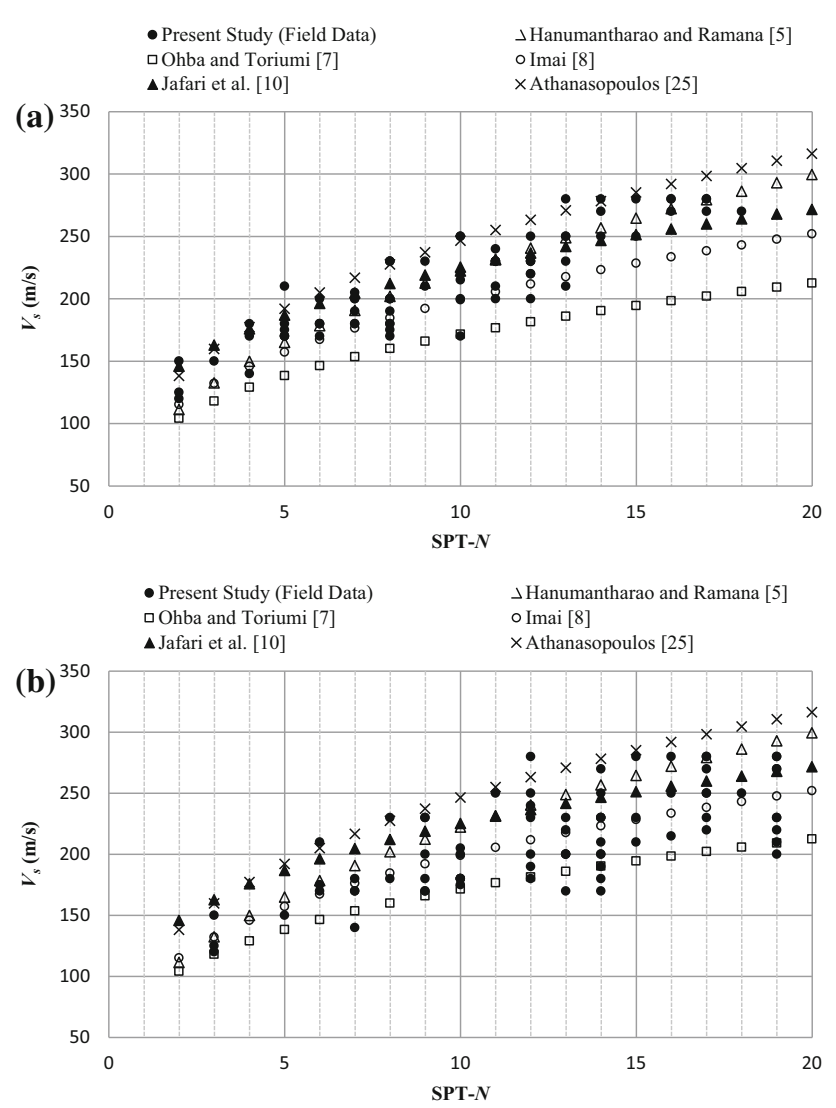

Fig. 5 a Comparison of uncorrected $V_{s}$ versus uncorrected $N$ for all soils b comparison of uncorrected $V_{s}$ vs corrected $N$ for all soils
$\left(N_{1}\right)_{60}=N \times C_{N}\left(\frac{E_{m}}{0.60 E_{f f}}\right)$

where,

$C_{N}=0.77 \log \left(\frac{2000}{\sigma_{v o}^{\prime}}\right)$

where, $\left(N_{1}\right)_{60}=$ corrected SPT blow count normalized to $60 \%$ energy, $N=$ measured SPT blow count in field, $E_{m}=$ actual hammer energy, $E_{f f}=$ theoretical free-fall hammer energy, $C_{N}=$ overburden correction factor and $\sigma_{v o}^{\prime}=$ effective overburden pressure at the depth of penetration in $\mathrm{kPa}$.

From Fig. 5a, b, it can be observed that this comparison is better for Fig. 5a because in Fig. 5b, many data pairs of present study are outside the range of previous researchers, therefore in further work uncorrected $N$ is used.

In Fig. 5a, for all these six data sets, it can be observed that Athanasopoulos [25] provide an upper bound and Ohba and Toriumi [7] provide a lower bound. All other four data sets lie between these two curves. Further, data of present study are very close to that presented by Jafari et al. [10] and Hanumantharao and Ramana [5]. Figure 6a, shows correlation between uncorrected $V_{s}$ and uncorrected $N$ for all soils and a relation is developed, the proposed relation between $V_{s}(\mathrm{~m} / \mathrm{s})$ and $N$ values for all soils is as follows. 


$$
V_{s}=99.5 N^{0.345}
$$

This relation has correlation coefficient $R^{2}=0.80$ which is reasonably good value. Figure $6 \mathrm{~b}$, shows correlation between uncorrected $V_{s}$ and corrected $N$ for all soils. This has following relation.
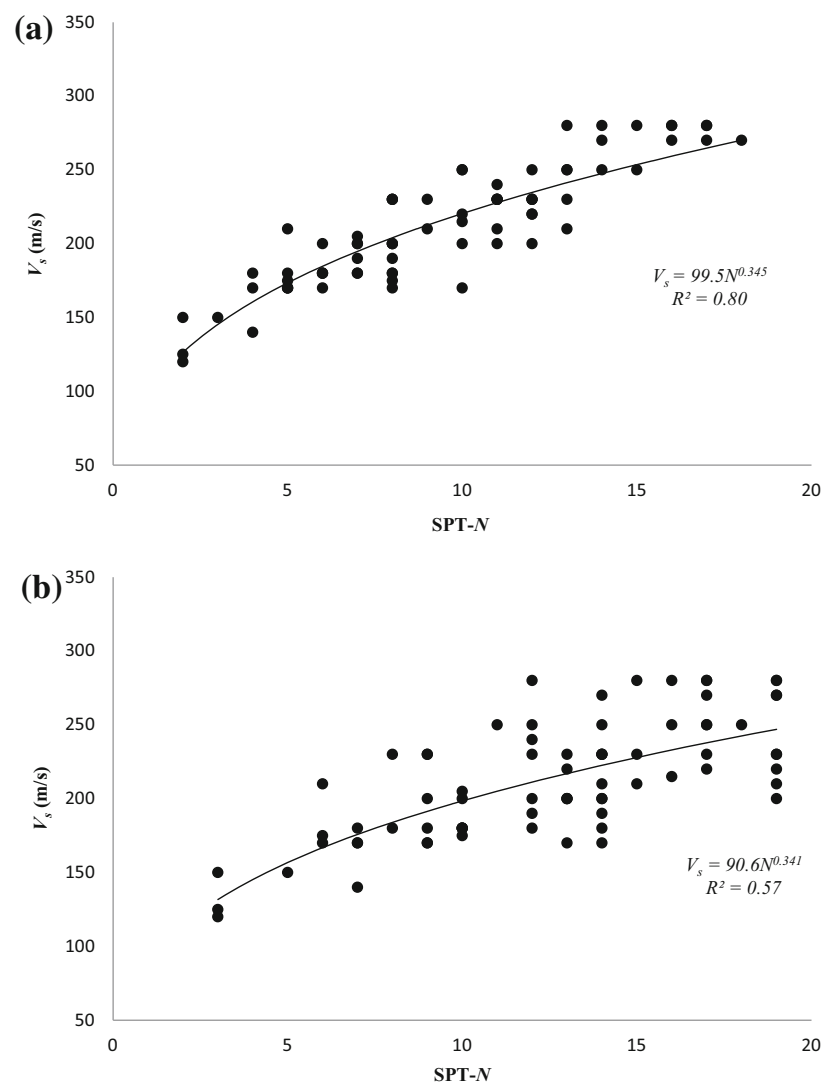

Fig. 6 a Correlation between uncorrected $V_{s}$ and uncorrected $N$ for all soils for present study b correlation between uncorrected $V_{s}$ and corrected $N$ for all soils for present study

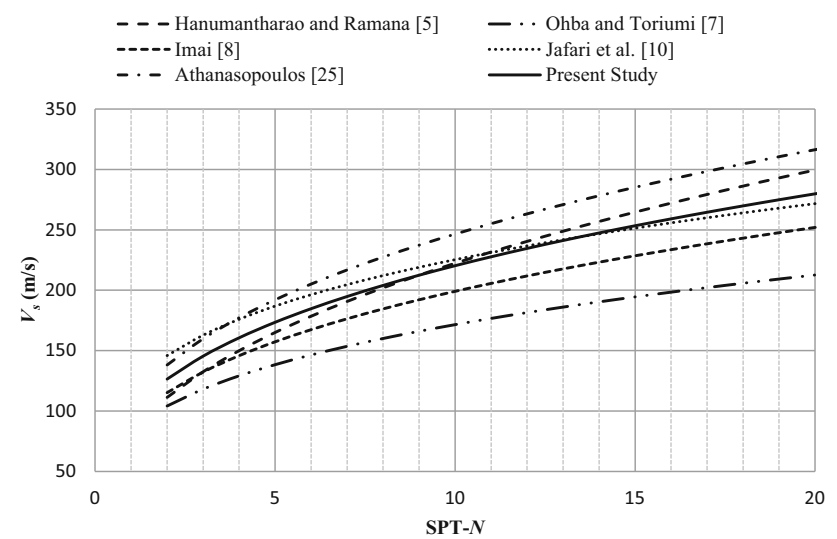

Fig. 7 Comparisons between proposed and previous correlations for all soils
$V_{s}=90.6 N^{0.341}$

This has correlation coefficient $R^{2}=0.57$, which is quite low value as compare to that for Eq. 3a. Therefore it also indicates that the better correlations are obtained using uncorrected $\mathrm{N}$ value. Figure 7 shows comparisons between proposed relation (Eq. 3a) and previous correlations for all soils. It can be observed that the curve of present study is well in the middle of all other curves, indicating a very good agreement.

\section{Sandy Soils}

Similar to all soils, the regression analysis was also carried out for sandy soils, Out of 74 data pairs, 53 were of sandy soils. In Fig. 8, field data of $V_{s}$ and $N$ for sandy soils are compared with the equations recommended by six other researchers i.e. Hanumantharao and Ramana [5], Maheshwari et al. [6], Imai [8], Okamoto et al. [23], Pitilakis et al. [24] and Raptakis et al. [26]. For all these seven data sets, it can be observed that Okamoto et al. [23] provide an upper bound and Imai [8] provide a lower bound. All other five data sets including present study lies between these two curves. Figure 9 shows correlation between $V_{s}$ and $N$ and proposed relationship between $V_{s}(\mathrm{~m} / \mathrm{s})$ and $N$ values for sandy soils is as follows.

$V_{s}=100.3 N^{0.338}$

This equation has correlation coefficient $R^{2}=0.83$, which is reasonably acceptable value. The proposed relationship for sandy soils (Eq. 4) is compared with existing relationships in Fig. 10. It is indicated that except the equation developed by Imai [8], the proposed equation (Eq. 4) is within the range of the other equations for the prediction of the $V_{s}$ of sands. It can be also observed that the equation of the present study (Eq. 4) is close to that of

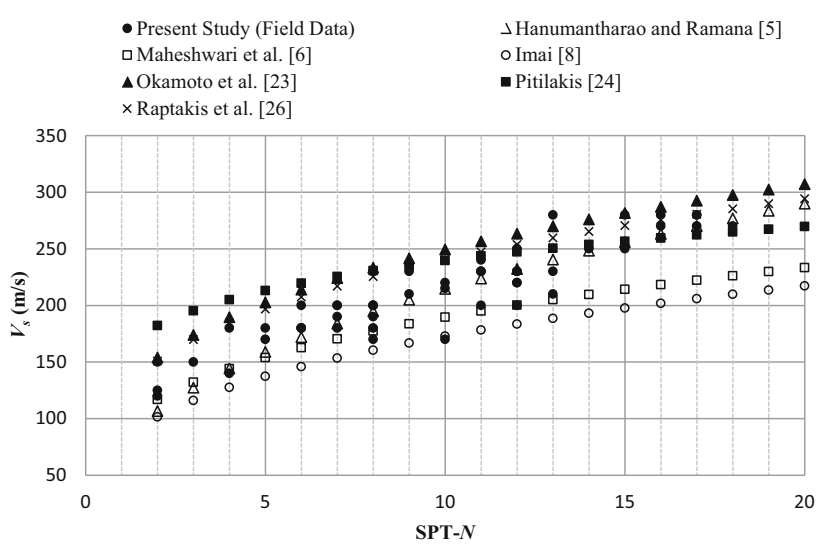

Fig. 8 Comparison of $V_{s}$ versus $N$ for sandy soils 
Hanumantharao and Ramana [5] for all the range of $N$ used and at higher $N(>14)$ the present relation best match with Pitilakis et al. [24].

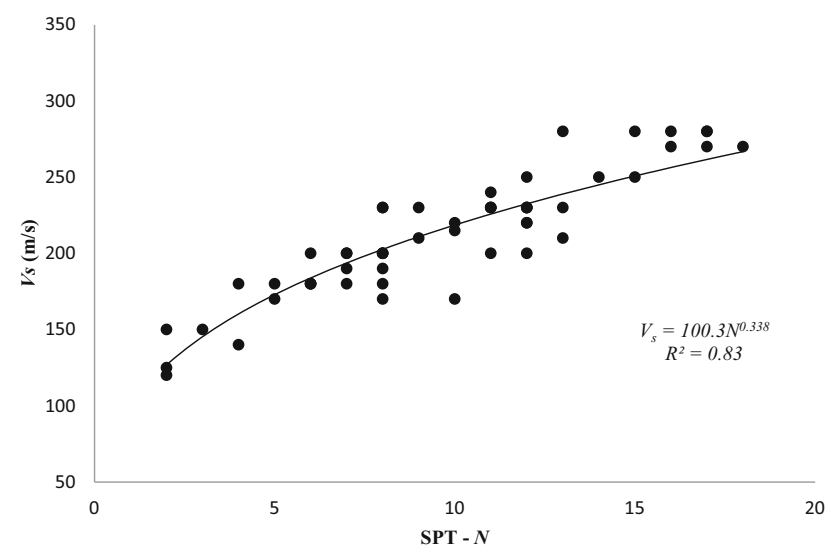

Fig. 9 Correlation between $V_{s}$ and $N$ for sandy soils for present study

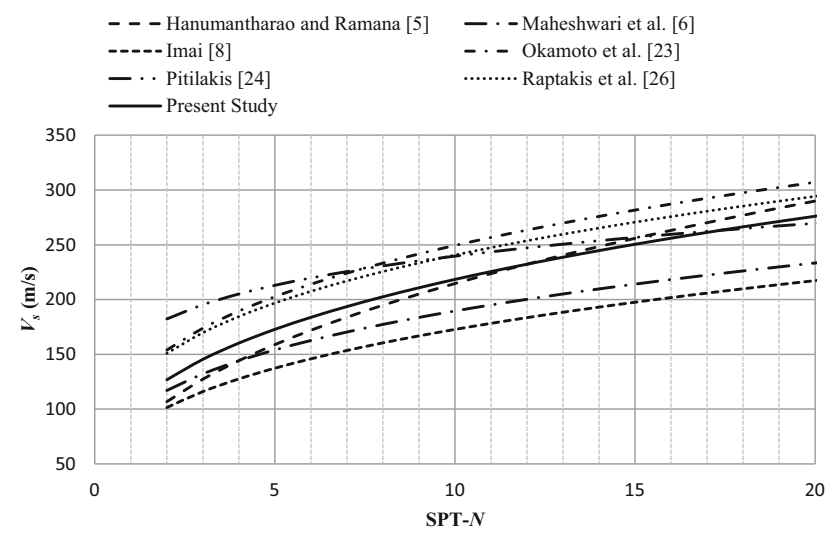

Fig. 10 Comparisons between proposed and previous correlations for sandy soils

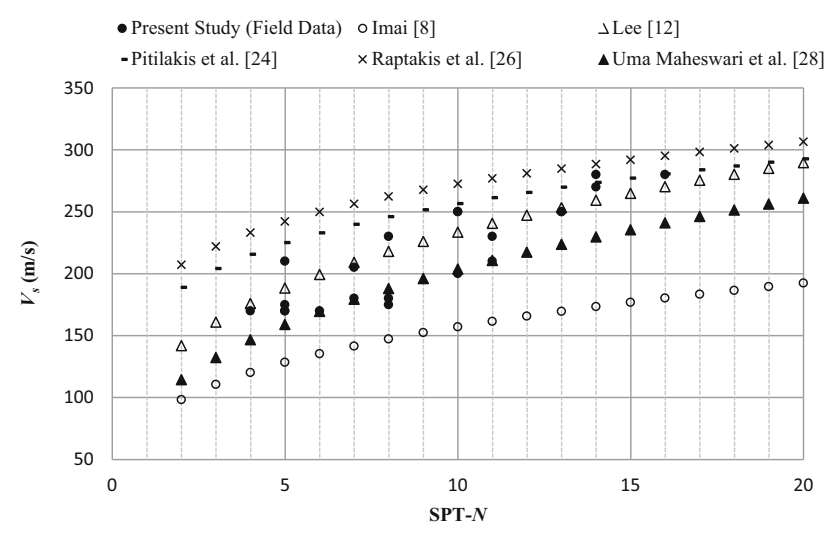

Fig. 11 Comparison of $V_{s}$ versus $N$ for clayey soils

\section{Clayey Soils}

For clayey soils, 21 data pairs $\left(V_{s}\right.$ and $N$ ) were employed in the regression analysis. The comparison of field data with the equations proposed by five other researchers i.e. Imai [8], Lee [12], Pitilakis et al. [24], Raptakis et al. [26] and Uma Maheswari et al. [28] are shown in Fig. 11. For all these 6 data sets, it can be observed that Raptakis et al. [26] provide an upper bound and Imai [8] provide a lower bound. All other 4 data sets (including present study) lies between these 2 curves. Correlation between $V_{s}$ and $N$ is shown in Fig. 12 and proposed relationship between $V_{s}(\mathrm{~m} /$ s) and $N$ values for clayey soils are given in following equation with correlation coefficient $R^{2}=0.73$.

$V_{s}=94.4 N^{0.379}$

The comparison of the proposed relationship (Eq. 5) for clayey soils with previous researchers is shown in Fig. 13. It can be observed that the result of present study is very close to that reported by Lee [12]. Further it is approximately near to that presented by Uma Maheswari et al. [28]

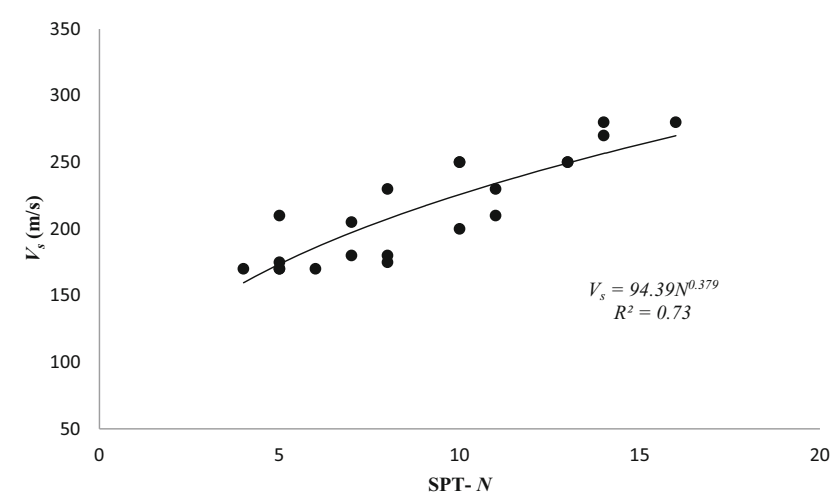

Fig. 12 Correlation between $V_{s}$ and $N$ for clayey soils for present study

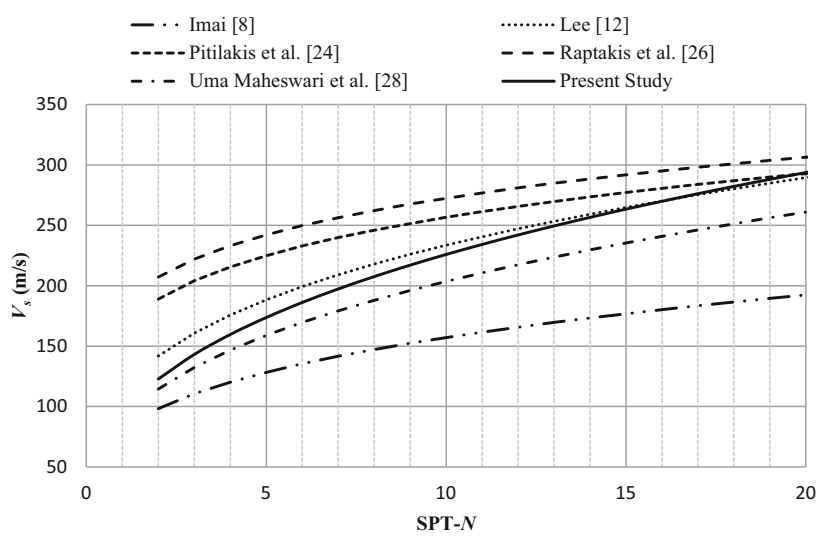

Fig. 13 Comparisons between proposed and previous correlations for clayey soils 
Table 4 Summary of the proposed relationships

\begin{tabular}{llll}
\hline S. no. & Type of soil & Correlation & $\mathrm{R}^{2}$ \\
\hline 1 & All soils & $V_{\mathrm{s}}=99.5 N^{0.345}$ & 0.80 \\
2 & Sandy soils & $V_{\mathrm{s}}=100.3 N^{0.338}$ & 0.83 \\
3 & Clayey soils & $V_{\mathrm{s}}=94.4 N^{0.379}$ & 0.73 \\
\hline
\end{tabular}

at lower $N$. However, the result presented by Imai [8] is on lower side.

Table 4, summarizes the proposed relationships and corresponding correlation coefficients. It is emphasized that number of blows $(N)$ used in Table 4 is uncorrected SPT blows. It can be observed that for present data pairs, the relationship of all soils and sandy soils are very close as in all soils most of the data pairs are that of sandy soils. However, the relationship for clayey soils is bit different than other two. Also, from Table 4 it clear that the correlation coefficient $\left(R^{2}\right)$ is highest for sandy soils and least for clays while intermediate for mixed soil. Thus it can be inferred that the correlation is better if fine contents are less.

\section{Summary and Conclusions}

In this study, an attempt has been made to develop new relationships between $V_{s}$ and $N$ for Roorkee region; this has been carried out for three cases separately i.e. (a) all soils (b) sandy soils and (c) clayey soils. For this, field tests i.e. SPT and MASW were conducted for ten sites in the region, the data collected are discussed in this paper. The major conclusions drawn from this study are

1. The sites with high fine contents have relatively higher $N$ values.

2. The effect of correction of $N$ values on proposed relationships has been examined and it was found that the uncorrected $N$ value gives better correlations.

3. The results obtained from this study supported the findings of earlier works. The proposed relationships (Table 4), lies within the range of other relations available in the literature for all three cases.

4. The proposed relations are almost at average values of the existing relations and thus compared well with most of the previous equations.

5. It was observed that the correlations is better if fine contents are less.

The relationships proposed in this paper are important as these may be used in the seismic microzonation of the area.
Such relationships are not reported previously for this region. These relationships can be used to find shear wave velocity $\left(V_{s}\right)$ as often $N$ values are readily available. The $\left(V_{s}\right)$ is a key parameter in ground response analysis which helps in finding amplification at a site. This in turn useful for evaluating damage during an earthquake and deciding about the extent of ground improvement to be carried out.

Acknowledgments For this research, the first and third authors were supported by MHRD, Government of India Fellowships. This support is gratefully acknowledged.

\section{References}

1. IS: 1893 (Part-1) (2002) Criteria for earthquake resistant design of structures: general provisions and buildings. Bureau of Indian Standards (BIS) New Delhi

2. Boominathan A, Dodagoudar GR, Suganthi A, Uma Maheswari $\mathrm{R}$ (2006) Seismic hazard assessment considering local site effects for microzonation studies of Chennai city. Proceedings of the a workshop on microzonation. Interline Publishing, Bangalore, pp 94-104

3. Japan Road Association (JRA) (1980) Specification and interpretation of bridge design for highway-part V: Resilient design

4. Sitharam TG, Anbazhagan P (2007) Seismic hazard analysis for the Bangalore region. Nat Hazards 40:261-278

5. Hanumantharao C, Ramana GV (2008) Dynamics soil properties for microzonation of Delhi, India. J Earth Syst Sci 117(S2): 719-730

6. Maheshwari BK, Mahajan AK, Sharma ML, Paul DK, Kaynia AM, Lindholm C (2013) Relation between shear velocity and SPT resistance for sandy soils in the Ganga basin. Int J Geotech Eng 7(1):63-70

7. Ohba S, Toriumi I (1970) Dynamic response characteristics of Osaka Plain. In: Proceedings of the annual meeting, AIJ (in Japanese)

8. Imai T (1977) P-and S-wave velocities of the ground in Japan. Proc IX Int conf Soil Mech Found Eng 2:127-132

9. Ohta Y, Goto N (1978) Empirical shear wave velocity equations in terms of characteristics soil indexes. Earthq Eng Struct Dyn 6:167-187

10. Jafari MK, Shafiee A, Razmkhah A (2002) Dynamic properties of fine grained soils in south of Tehran. Soil Dyn Earthq Eng 4(1):25-35

11. Seed HB, Idriss IM (1981) Evaluation of liquefaction potential sand deposits based on observation of performance in previous earthquakes. ASCE National Convention, Missouri, pp 81-544

12. Lee SHH (1990) Regression models of shear wave velocities in Taipei basin. J Chinese Inst Eng 13:519-532

13. IS: 2131 (1981) Method for standard penetration test for soils. Bureau of Indian Standards (BIS) New Delhi

14. Kirar B, Maheshwari BK (2015) Dynamic properties of soils at large strains in Roorkee region using field and laboratory tests. In: Review Geotech Testing Jounal, ASTM submitted Nov. 2015

15. Muley P, Maheshwari BK, Paul DK (2015) Liquefaction potential of Roorkee region using field and laboratory tests. Int $\mathbf{J}$ Geosynth Ground Eng 1(4):37

16. IS: 2720 (Part 4) (1983) Methods of test for soils: Grain size analysis. Bureau of Indian Standards (BIS) New Delhi

17. IS: 2720 (Part 3) (1980) Methods of test for soils: determination of specific gravity. Bureau of Indian Standards (BIS) New Delhi 
18. IS: 2720 (Part 14) (1986) Methods of test for soils: Determination of density index (Relative Density) of cohesionless soils. Bureau of Indian Standards (BIS) New Delhi

19. Rix GL, Lai CG, Orozco MA, Hebeler GL, Roma V (2001) Recent advances in surface wave methods for geotechnical site characterization. In Proceedings of the XV International conference on soil mechanics and geotechnical engineering, Istanbul

20. Hunter JA, Benjumea B, Harris JB, Miller RD, Pullan SE, Burns RA, Good RL (2002) Surface and downhole shear wave seismic methods for thick soil investigations. Soil Dyn Earthq Eng 22(9-12):931-941

21. Park CB, Miller RD, Xia J, Ivanov J (2007) Multichannel analysis of surface waves (MASW): active and passive methods. Lead Edge 26(1):60-64

22. Sykora DE, Stokoe KHII II (1983) Correlations of in situ measurements in sands of shear wave velocity. Soil Dyn Earthq Eng 20(1-4):125-136

23. Okamoto T, Kokusho T, Yoshida Y, Kusuonoki K (1989) Comparison of surface versus subsurface wave source for $\mathrm{P}-\mathrm{S}$ logging in sand layer. In Proceedings of the 44th Annual Conference, JSCE 3 pp 996-997

24. Pitilakis KD, Anastasiadis A, Raptakis D (1992) Field and laboratory determination of dynamic properties of natural soil deposits. In Proceedings of the 10th world conference on earthquake engineering, Rotterdam, pp 1275-1280
25. Athanasopoulos GA (1995) Empirical correlations Vso-NSPT for soils of Greece: a comparative study of reliability. Proceedings of the 7th International Conference on Soil Dynamics and Earthquake Engineering Computation Mechanics Publications. Southampton, Boston, pp 19-25

26. Raptakis DG, Anastasiadis SAJ, Pitilakis KD, Lontzetidis KS (1995) Shear wave velocities and damping of Greek natural soils. In Proceedings of the 10th European conference on earthquake engineering, Vienna, pp 477-482

27. Hasancebi N, Ulusay R (2007) Empirical correlations between shear wave velocity and penetration resistance for ground shaking assessments. Bull Eng Geol Environ 66:203-213

28. Uma Maheswari R, Boominathan A, Dodagoudar GR (2010) Use of surface waves in statistical correlations of shear wave velocity and penetration resistance of Chennai soils. Geotech Geol Eng 28:119-137

29. Esfehanizadeh M, Nabizadeh F, Yazarloo R (2015) Correlation between standard penetration $\left(\mathrm{N}_{\mathrm{SPT}}\right)$ and shear wave velocity $\left(\mathrm{V}_{\mathrm{s}}\right)$ for young coastal sands of the Caspian Sea. Arab J Geosci 8:7333-7341

30. Fatehnia M, Hayden M, Landschoot M (2015) Correlation between shear wave velocity and SPT-N values for North Florida soils. Elec J Geotech Eng 20:12421-12430 